\title{
Creating and Promoting Gender Equity and Diversity in Professional Geological Societies
}

Kernen, R. ${ }^{1}$, Abu, C. ${ }^{2}$, Allen, J. ${ }^{3}$, Ahmed, S. ${ }^{4}$, Avary, K. L. ${ }^{5}$, Birgenheier, L. ${ }^{6}$, George, T. ${ }^{7}$, Gomez, K. ${ }^{8}$, López Vega, A. ${ }^{9}$, Onwumelu, C. ${ }^{10}$, Rysak, B. ${ }^{8}$, Hart-Wagoner, N ${ }^{11}$

1 University of Adelaide, Australian School of Petroleum \& Energy Resources, rachelle.kernen@adelaide.edu.au, Twitter: @sed_salt_belle

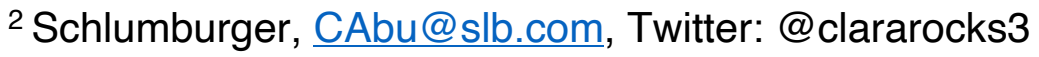

33Chevron, jonathan.allen@chevron.com, Twitter: @therockdoctor_

4Texas A\&M, College Station, sumiyyah@gmail.com, Twitter: @geogen2020

${ }^{5}$ Avary Geoscience, avarygeo@gmail.com

${ }^{6}$ The University of Utah, Geology and Geophysics Department, lauren.birgenheier@utah.edu, Twitter: @gloriouslymuddy

${ }^{7}$ EOG Resources, terra george@eogresources.com

8The University of Texas at Austin, Department of Geological Sciences, kiaragomez@utexas.edu, Twitter: @KiaraJGomez1 bethany.rysak@utexas.edu

9Total, andrea.lopez@total.com

10The University of North Dakota, Harold Hamm School of Geology and Geological Engineering, chioma.onwumelu@und.edu, Twitter: @c_h_i_o_m_a

11Unaffiliated, hartnic4@gmail.com, Twitter: @hartnic4

Please note this is a non-peer reviewed pre-print submitted to EarthArXiv.

This manuscript is currently under peer-review through the American Association of Petroleum Geologists (AAPG) Bulletin

Bulletin (aapg.org) 
Abstract

Diversity drives innovation. When professional organizations allow gender inequity to persist, they continually lose talented, valuable individuals who drive economic growth and profits. According to membership data collected by the American Association of Petroleum Geologists (AAPG), American Geophysical Union (AGU), and

51 the Geological Society of America (GSA) there is evidence of continued gender inequity

52 in professional geological societies, particularly, in the AAPG. Specifically, there are

53 remaining inequities in the percentage of women holding leadership and technical

54 positions, publishing articles, giving distinguished lectures, and receiving technical and

55 service awards within AAPG, even when compared to the proportional percentage of AAPG members. Because the AAPG is a major international geoscience professional organization, this inequity greatly contributes to the gender and diversity disparity that we see today in the greater geoscience community. The recent compilation and comparison of historical AAPG award and leadership role data allow for an opportunity to provide solutions to advance gender equity and give meaningful power to diversity in AAPG's most visible and prestigious opportunities. By addressing this issue and implementing meaningful measures to improve gender equity, professional societies such as AAPG, can demonstrate tangible efforts to eliminate the discrimination, bias, and barriers many women encounter and support women in having equitable

65 opportunities as professional geoscientists. 


\section{Introduction}

In the last decade, there have been significant efforts to recruit greater numbers

78 of women into science-technology-engineering-math (STEM) fields, spanning pre-K

79 through undergraduate education. Geoscience enrollment and degree trends indicate

80 these efforts have been generally successful. From 2010-2017, data published by the

81 American Geosciences Institute (AGI; Gonzales, 2019) indicates that enrollment and

82 graduation rates of women with B.S., M.S., and Ph.D. degrees in geological sciences

83 have remained steady between roughly $35-45 \%$ as compared to roughly $20-25 \%$ in

84 1985. With continued recruiting efforts, it is hoped the percent of women with

85 geoscience degrees will rise to an even more equitable level.

Despite relatively successful recruiting efforts, current data indicate significant

87 inequity persists in the gender distribution of professionally employed geoscientists.

88 During the same period as above (2010-2017), data from the National Science

89 Foundation (NSF) and AGI indicate that the percentage of women with geoscience

90 degrees working as geoscientists decreased from $17 \%$ to $11 \%$. While historically high

91 percentages of women earn geoscience degrees, those percentages crumble to roughly

92 half of women employed as professional geoscientists compared to their male

93 counterparts (Gonzales, 2019). These statistics were also compared with the American

94 Association of Petroleum Geologists (AAPG) membership data which indicate that

95 women membership has hovered between $19-21 \%$ since 2014 and prior to that, it was

96 significantly less $(<18 \%)$.

97 Historically, gender inequality has been linked to a lack of visible role models and 98 workforce retention issues (Gonzales, 2019; Newton, 2012, Popp et al., 2019). Low

99 retention can result in a "leaky pipeline" where not nearly as many candidates who enter

100 the profession in college obtain a job in the geosciences (Holmes et al., 2008). Further

101 attrition occurs as many women leave the workplace at higher rates than men

102 throughout their careers (Fouad et al. 2017; Cech and Blair-Loy, 2019). Several studies

103 have identified factors that contribute to leaks in the pipeline, which include a lack of

104 visible sponsors; limited mentors and advisors; emotionally unsupportive classroom and 105 work environments; gender-based isolation and discrimination; biased or nepotistic 
106 hiring and lay-off practices; 'family-unfriendly' policies; poor marketing of geoscience

107 programs to minorities and women; a difference in career goals between men and

108 women; and low self-confidence and self-efficacy among women and minority

109 geoscientists (Baber et al., 2018; Callahan et al., 2015; Ceci et al., 2011; Estrada et al.,

110 2018; Holmes et al., 2008; Holmes and O'Connell, 2003; Stokes et al., 2015; Williams, 111 2012; Williams, 2017).

112 These inequities are not only observed in the workforce but also in professional

113 organizations. Visible women in prestigious geoscience leadership positions, awards,

114 publications, distinguished lectures, and technical roles are underrepresented relative to

115 men and relative to the total percentage of women scientists within geoscience

116 professional society membership (Lincoln et al., 2012; Holmes et al., 2015; Fernandes

117 et al., 2020). Women of color are rarely nominated or selected for these positions and

118 awards, falling into "the double bind" or "double jeopardy" phenomena (Malcom et al.,

119 1975; Ceci et al., 2014). Recent data clearly indicate that the ongoing impact of implicit

120 and explicit bias on women's careers is real and significant (Eaton et al., 2020; Huang

121 et al., 2020) and is even more detrimental for women of color (Dutt, 2019). Implicit and

122 explicit bias over the length of a woman's career severely limits the diversity of the

123 candidate pool for prestigious leadership positions, technical and service awards,

124 publications, distinguished lectures, and technical roles within geologic societies further

125 causing gender inequality. Systemic inequities leave women constantly "swimming

126 upstream" or "working against a headwind" which leads to less wealth, burn out, and

127 systemic mental and physical health issues (Hagni, 1985; Kotok, 2007).

128 AAPG is an internationally leading professional geoscience society, with strong

129 ties to the private energy industry workforce. Because the energy industry is a major

130 employer of professional geoscientists, many geoscience professionals globally rely on

131 the AAPG for networking, training, and professional opportunities. Since it plays a

132 major role in the geoscience workforce landscape, examining metrics of gender equity

133 within AAPG is critical to continued efforts to diversify the workforce and, hence,

134 innovation. Women within AAPG are more likely to be nominated and elected to service

135 roles (such as 'Secretary'); ultimately the time working in service roles taxes their 
136 careers and hinders them from being as competitive for more prestigious technical roles

137 and awards and submitting first-author papers for publication (Witze, 2016; Lerback \&

138 Hanson, 2017; Pico et al., 2020). Furthermore, other major geoscience professional

139 organizations have completed studies examining the internal gender balance of key

140 roles (e.g., Fernandes et al., 2020), but a similar self-introspective study of AAPG is

141 lacking.

142 The goals of this study are to 1) utilize available data from AAPG to evaluate the 143 percentage of women who have held leadership or technical roles, won technical or

144 service awards, published papers in society journals, or held distinguished lecturer

145 positions within AAPG, 2) compare data to related geoscience professional

146 organizations like GSA and AGU, and 3) provide recommendations for future initiatives

147 based on the results of the data analysis and documented literature.

148

149

150

151

152

153

154

155

156

157

158

159

160

161

162

163

164 


\section{Data Analysis}

Data recording the gender distribution utilized in this study were compiled from

168 annual reports within each respective organization. Data presented in this study have

169 been compiled in collaboration through personal knowledge and public website

170 information and represent the authors' perception of gender identity rather than an

171 individual's own self-reported identity. Currently, the only demographic data that AAPG

172 collects are age and gender (binary), whereas race, ethnicity, disability status, and

173 sexual orientation are not collected. This analysis is therefore incomplete and more

174 robust data collection is needed for a thorough analysis.

175 AAPG Leadership

176 Since 1917 there have been 1,138 executive committee leadership positions

177 within AAPG and its divisions (Division of Professional Affairs-DPA; Division of

178 Environmental Geoscientists-DEG; Energy \& Minerals Division-EMD). A total of 145

179 women (13\%) have held leadership positions since the first woman was elected in 1987

180 (Fig. 1). Since that time, women have held leadership positions every year except for

181 1994, with the percent of men to women ranging from 1.8 to 21 (5.5 average). The

182 percentage of women in leadership has been increasing overall and since 1987, the

183 percentage of women in AAPG leadership is higher than the percentage of women

184 members for 31 out of the 34 years. 2020 marks the largest number of women in

185 leadership, with women holding 10 (46\%) of the 22 positions. Over the last 10 years

186 (2011-2020), Secretary and Editor are the positions women are most often held by

187 women, with the position of Secretary being the only position where women have held 188 office more than men. 


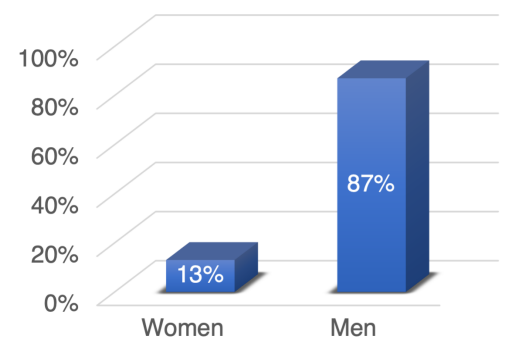

\section{AAPG Awardees}
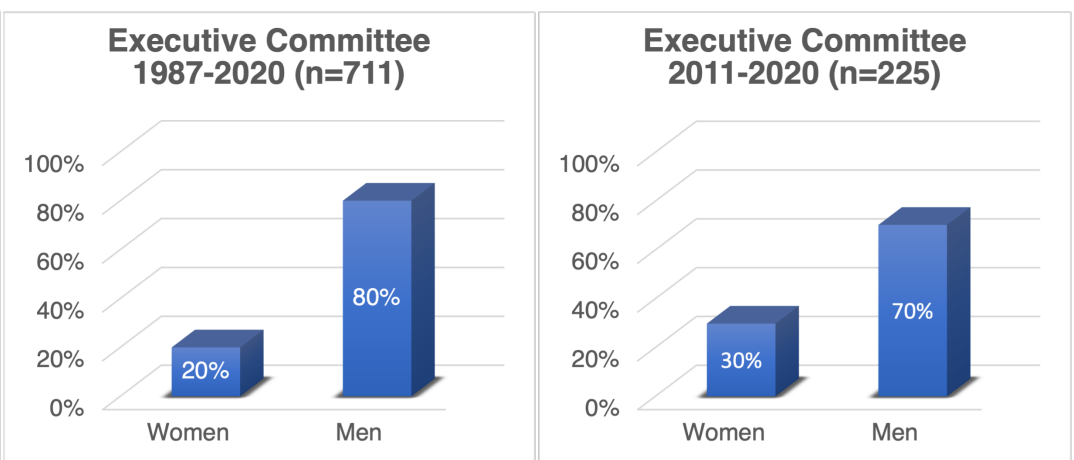

Figure 1: The number of men versus women in AAPG's Executive Leadership Committee from 1917-2020, 1987-2020, and 2011-2020. rates. Since 1917, there have been 3,932 awards granted by the association, including the AAPG Foundation. A total of 3,348 (85\%) awards have been received by men and $497(13 \%)$ have been received by women (Fig. 2). If the number of awardees whose sex is unknown (largely due to gender uncertain names, e.g., R.D. Smith) were included as women awardees, this number would increase to $584(15 \%)$. Almost half (49\%) of all awards that have recognized women were received in the last decade.

The first award that was received by a woman was granted in 1963 (Dollie Radler Hall; Honorary Member). Since 1975, at least one award was presented to a woman awardee every year. In 2017, 30 (22\%) women received awards, which was the largest recognized in a single year. Over the last 10 years (2011-2020) the ratio of men to women award recipients ranged from 3.2 to 7.1 (4.6 average). The Young Professionals Exemplary Service Award is the only award with equal gender representation since its inception in 2017 (Fig. 3). A woman has never received AAPG's highest honor, the Sidney Powers Memorial Award. The percentage of women recognized by AAPG awards has been higher than the percentage of women members

211 for only 3 of the last 10 years. This is in dramatic contrast to the percentage of women

212 in leadership positions, which has been greater than the percentage of women

213 members every year of the last decade. 

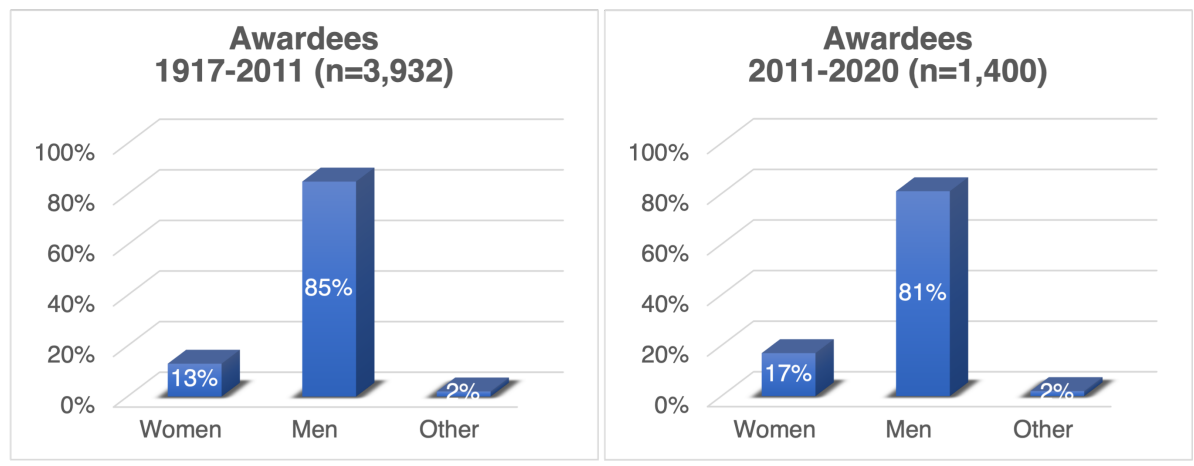

Figure 2: The number of men versus women (including unknown and other genders)

AAPG awardees from 1917-2020 and 2011-2020.

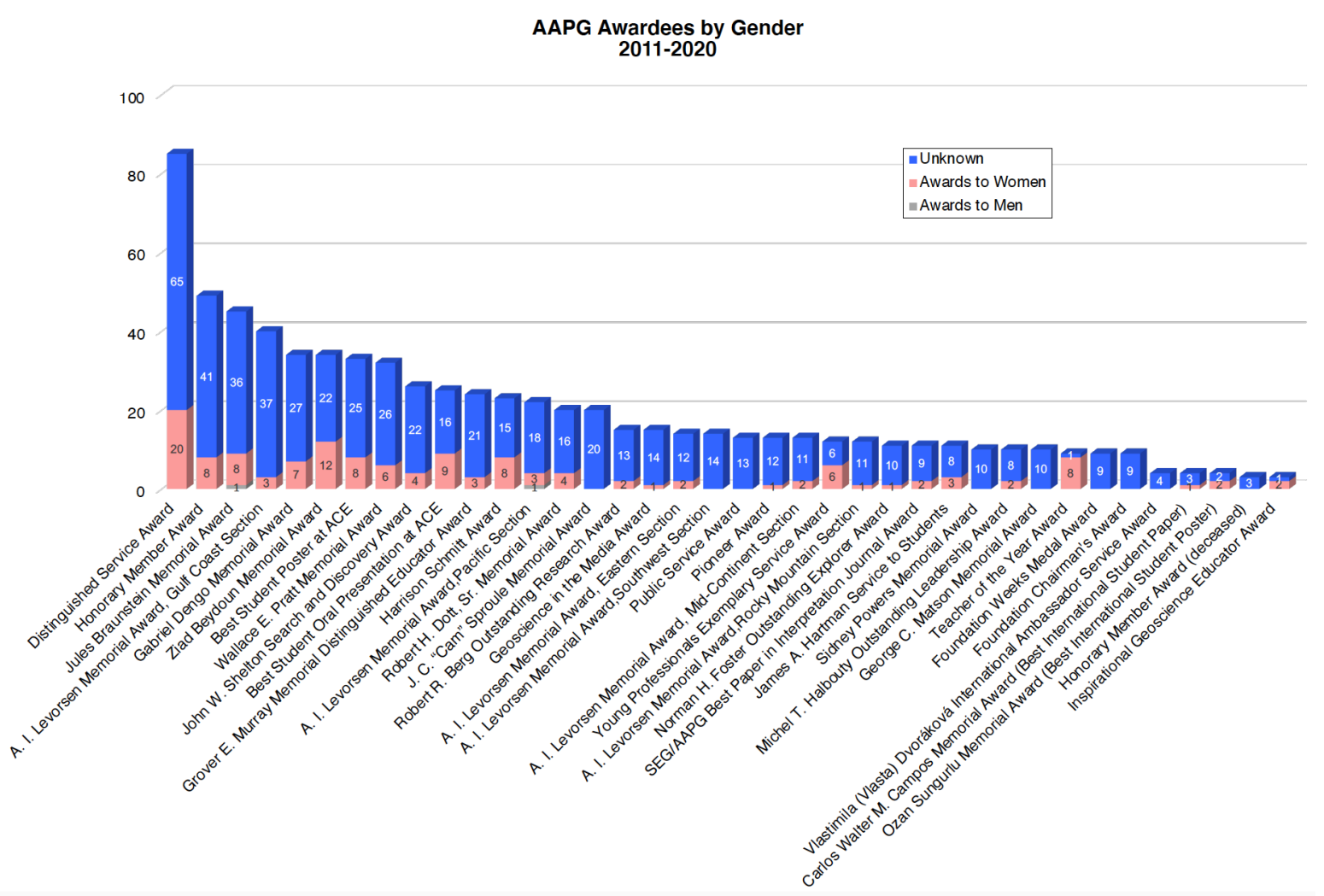

Figure 3: The number of men versus women (including unknown and other genders)

222 AAPG Publications, Distinguished Lecturers, \& Technical Roles

223 The previous and current editorial teams for AAPG's publications lack diversity

224 and equity. Editorial teams for the AAPG Bulletin include 28 men (72\%) and 11 women 
225 (28\%), Environmental Geoscience includes 22 men (73\%) and 8 women (27\%),

226 Interpretation includes 30 men (86\%) and 5 women (14\%), and the last 10 years of

227 AAPG Special Publications includes 85 men (84\%) and 16 women (16\%). Since 1961,

228 there have been 690 Distinguished Lecturers with just 48 (7\%) women (Fig. 4). The first

229 woman Distinguished Lecturer served in 1982. Over the last decade, the percentage of

230 women Distinguished Lecturers has increased to $20 \%$ but within a given year this is

231 highly variable, ranging from $9 \%$ to $67 \%$.

232 AAPG lists instructors available for lectures and short courses on the

233 organization's website, and therefore represents the most visible venue to examine the

234 diversity of the instructor pool. Of the 130 instructors listed, only $12(9 \%)$ are women.

235 Additionally, members who have volunteered to give short presentations to colleges and

236 universities, known as Visiting Geoscientists, are also available on the AAPG website.

237 Of the 152 Visiting Geoscientists, 27 (18\%) are women. Both of these percentages are

238 lower than the current percentage of women AAPG members (21\%).
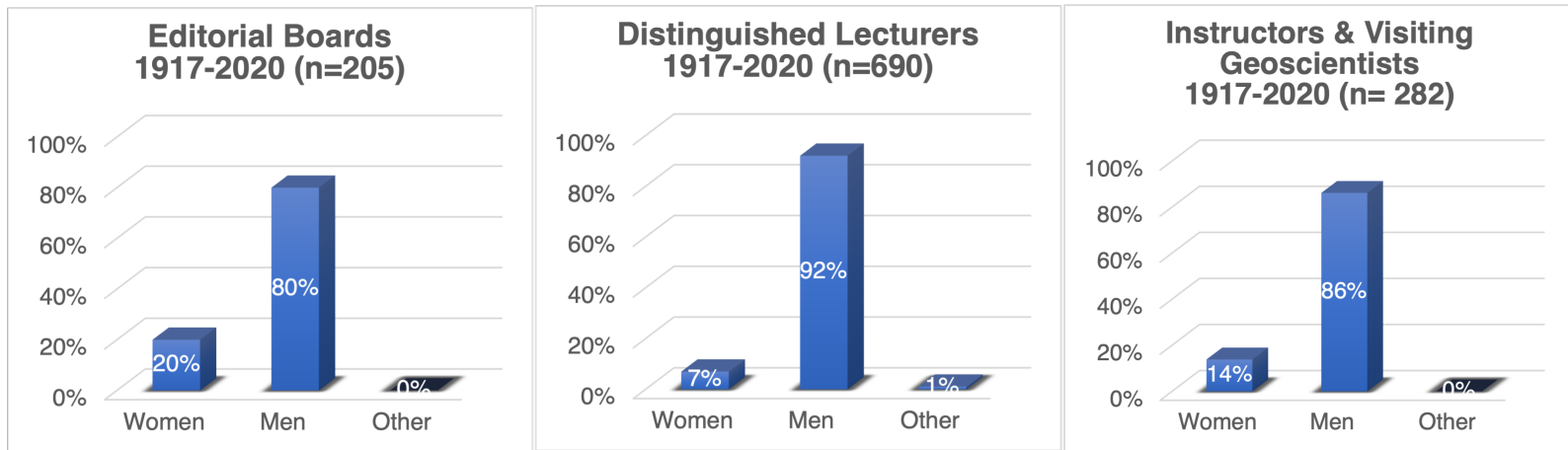

Figure 4: The number of men versus women (including unknown and other genders) to

Comparison to Other Geologic Organizations

Positions).

247 and membership data were either readily available or provided (Fig. 5). In comparison

248 with the Geological Society of America (GSA) and the American Geophysical Union 
249 (AGU), AAPG awardees are not representative of the AAPG membership and are the 250 least representative of the three organizations. Please note that AGU's women

251 awardees are only AGU Fellows. AGU has numerous awards, medals, and prizes, both

252 at the Union level and at the section levels (i.e., subgroups based on scientific

253 disciplines). The AGU Fellow was used because it is undeniably one of the highest

254 honors bestowed by AGU and is the largest group of honorees and is the most

255 consistent dataset going back to the 1960's. A striking observation is that the

256 percentage of AAPG women members is significantly less than the women members of

257 both GSA and AGU. Not only does AAPG lack equitable representation of women in

258 leadership, awards, and technical positions, the organization also struggles attracting

259 women members as compared to other professional geologic societies.

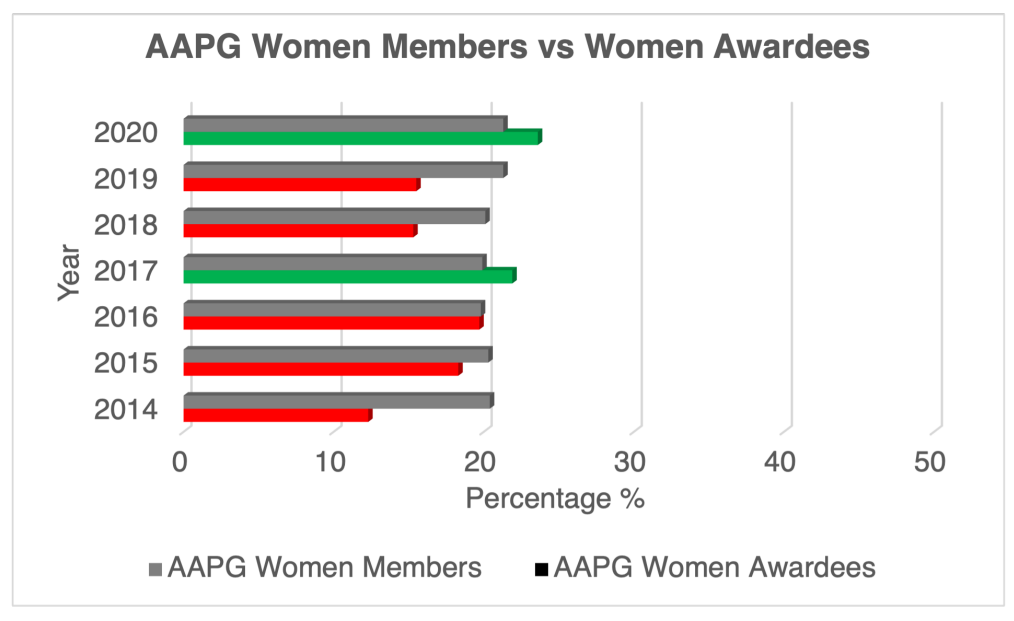




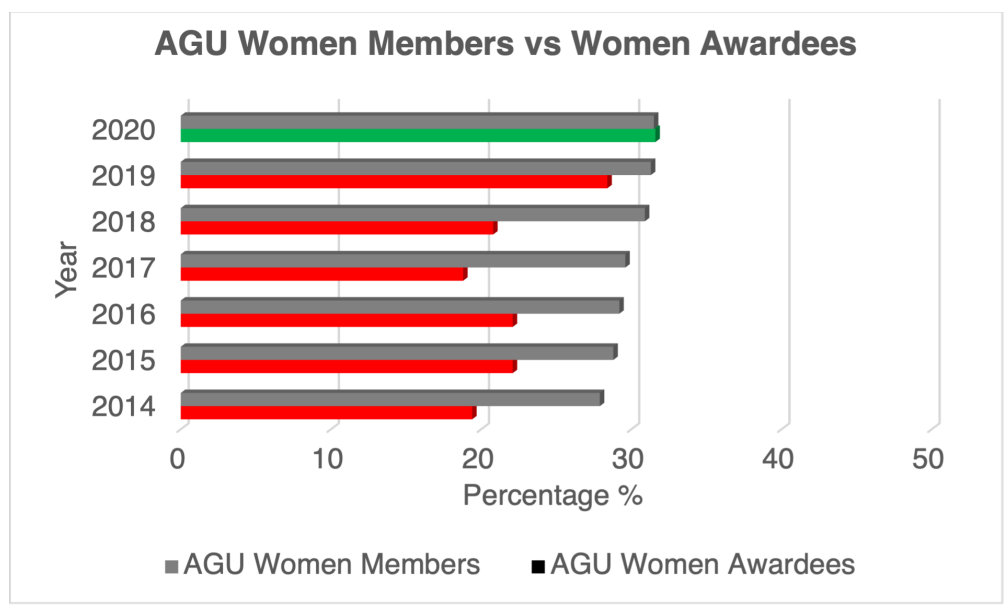

GSA Women Members vs Women Awardees

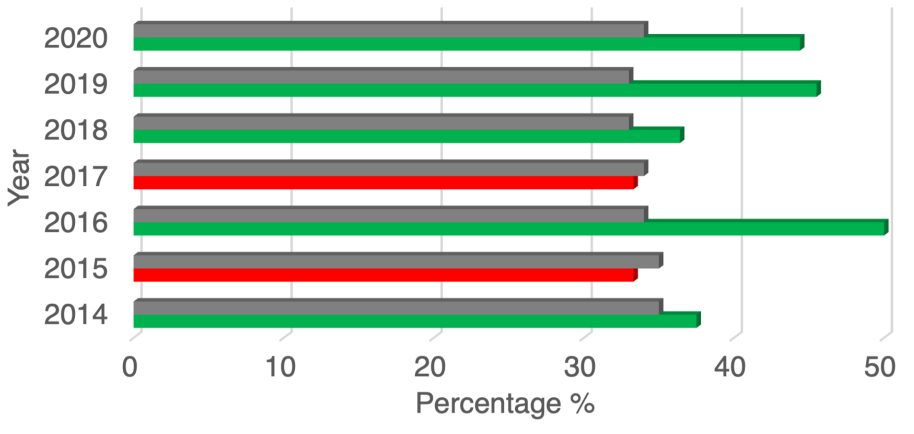

- GSA Women Awardees

265 Figure 5: The percentage of women awardees compared to the overall percentage of 266 women members. Red indicates years when women were underrepresented relative to the membership percentages, while green indicates years when women were appropriately represented. 


\section{Call to Action}

AAPG needs to increase representation of all under-represented groups by supporting the AAPG Women's Network Special Interest Group (SIG) to elevate it's status by become a Division and to support all initiatives put forth by the STEMulating Diversity SIG. Although some professional geological societies are trending toward gender equity, there are still many initiatives geological societies can implement to increase women membership and representation. While these recommendations are specific to AAPG, many of these initiatives can and should be implemented within other professional societies.

In order to increase women membership and participation, it is imperative AAPG

287 takes significant steps to eliminate sexual harassment, discrimination, and

288 microaggressions related to AAPG participation and activity. To ensure a high standard 289 of professional behavior, programs supporting justice, equity, diversity, and inclusion 290 (JEDI) need to be implemented and participation is a requirement for all staff and 291 volunteers. AAPG lags behind other large geoscience organizations, like GSA and 292 AGU, in JEDI efforts, programs and framework (Fig. 5). Women need to be 293 appropriately represented at all levels within the organization and, at a minimum, match 294 the percentage of women membership.

295 The authors recommend that AAPG collect member demographic data (within 296 the confines of local privacy laws) in order to establish metrics in which to benchmark 297 JEDI efforts and programs. In order to facilitate future JEDI efforts AAPG needs to 298 collect data based on the gender spectrum (two spirit, transgender women, transgender 299 man, questioning, pangender, non-binary, intersex, gender nonconforming, gender fluid, 300 genderqueer, Cis woman, Cis man, agender) race, ethnic background, and disabilities 301 such as physical, communication (hearing, speech, color blindness), intellectual and 302 emotional (autism, bipolar). These results need to be published yearly (anonymously) 303 to ensure transparency and appropriate solutions. At a minimum and at all levels, 304 AAPG needs to be gender, racial, and ethnically balanced with respect to AAPG's 305 overall membership statistics. To address inappropriate and unprofessional behaviors, a 306 confidential protocol (through the Code of Ethics) needs to be implemented in order to 
307 report JEDI violations and abuse. Such a protocol would ensure violations are handled 308 professionally and with the appropriate consequences to ensure no emotional or 309 professional 'backlash' or 'blacklisting' to the victim(s). Appropriate and fit-for-purpose

310 disciplinary action needs to swiftly take place in order to build trust within the 311 membership.

312 In addition to JEDI policies and procedures, women need to be nominated for 313 AAPG awards and positions by their peers in significantly higher numbers. In order to 314 work towards addressing this issue, the AAPG Women's Network has established a 315 committee to oversee women's resumes, AAPG activity, and service records in an 316 evergreen database so applications can be tracked and easily submitted for award and 317 position nominations. The procedures that AAPG uses to determine the recipients of 318 AAPG awards and positions need to be transparent and publicly available to ensure 319 JEDI policies and procedures are being honored and enforced. It's absolutely vital that 320 the women of AAPG embrace and closely work alongside the men who advocate for 321 them (ALLY) within the organization.

322 AAPG is failing its women membership and it is perpetuating gender inequity that 323 results in the loss of incredible talent in the energy industry (Fig. 5). Representation and 324 equity go far beyond 'awarding an equitable number of women awardees and leaders to 325 the percentage of membership'. Pigeonholing women in service, support, and teaching 326 roles instead of leadership positions ultimately hinders them from being competitive for 327 more prestigious technical roles, awards, and submitting first-author papers for 328 publication (Witze, 2016; Lerback \& Hanson, 2017; Pico et al., 2020). Because women 329 are less competitive due to their extensive service, support, and teaching roles, they 330 never actually make it to the highest levels of leadership among professional societies, 331 academic institutions, or C-Suite industry positions. Professional geologic organizations 332 should not take their role in influencing the membership's careers lightly; a higher 333 standard of overall equity, conduct, and eliminating sexual harassment needs to be 334 resolved for the profitability of the organization and the well-being of its membership 335 (Marín-Spiotta et al., 2020). 
To further increase participation and membership across all levels, a cultural

337 transformation is greatly needed within AAPG to support gender equity. AAPG must

338 include under-represented minority members and students within conversations,

339 leadership positions, award nominations, as they will be the next generation of leaders.

340 We can tackle the issue of increasing minority membership by actively seeking out

341 female minority students and professionals to be more involved, as well as including

342 them in decision-making conversations and highlighting their achievements. Within the

343 female minority group, there are first-generation students who are often lost in

344 navigating the AAPG community due to lack of mentoring and sponsorship. AAPG

345 should include minorities and consider appropriate practices for recruiting and retaining

346 a diverse population.

\section{Conclusions}

In order for the AAPG and other professional geological societies to be financially successful and technically innovative in the future, they need to embrace and uplift female and minority populations (and all other marginalized members) by becoming

352 more diverse and inclusive. We provided a base framework of demographic data 353 needed to analyze gender equity and diversity across all professional societies and 354 organizations. Specifically, race and gender data need to be collected and published 355 publicly for members of AAPG to view and to provide a reference point for future 356 assessments of JEDI. We provide evidence that highlights how and why JEDI is 357 important and highly encourage a cultural shift to take place within the greater AAPG 358 organization. We recommend that the AAPG reports and handles all types of 359 harassment and bullying, with increasing women's roles at all levels of the organization 360 (from session chairs, to Distinguished Lecturers, and leadership). By supporting the 361 Women's Network Division and STEMulating Diversity SIG, it will allow JEDI practices 362 to have greater influence over the AAPG community, however it is not the sole 363 responsibility of those networks. It is important for each member, leader, and staff 364 member of the AAPG to be informed about the gender, racial, and ethnic inequities and 365 to embrace the AAPG community by not only improving the statistics but improving the 
overall experience of AAPG communications and activities. Our hope is that the AAPG will embrace the Women's Network and STEMulating Diversity in order to provide structure and support to the rest of the organization and implement the processes required for a culture shift to take place.

Not only do women and minorities need to be recognized at all levels of the organization in equal proportions (from session chairs, to Distinguished Lecturers, and

372 leadership), but cultural bias including the expectation that women and minorities do the 373 majority of 'service work' needs to change. Women and minorities need to be 374 nominated for many more technical roles, awards, and submit first-author papers for 375 publication in the AAPG Bulletin. Additionally, early and mid-career scholarships 376 targeting a diverse set of recipients need to be established in order to help solve the 377 systemic disadvantages that women and minorities face in the energy geosciences. "If you want to be a true professional, do something outside yourself."

\section{Acknowledgements}

Ruth Bader Ginsburg

The AAPG Women's Network would like to acknowledge the AAPG leadership for reviewing and allowing us to publish AAPG's data in the peer reviewed AAPG Bulletin. The leadership of AAPGWN sincerely thanks the Geological Society of America (GSA) Executive Director Vicki McConnell and American Geophysical Union (AGU) Director for Business Data and Intelligence Karine Blaufuss for working with their staff to provide datasets that could be compared to the AAPG data. Special thank you to Dr. Christine Williams, Professor of Sociology and the Elsie and Stanley E. (Skinny) Adams Sr. Centennial Professor in Liberal Arts from The University of Texas at Austin for hosting mentoring sessions with the authors and providing some of the appropriate 
References

397 Baber, L.D., Pifer, M.J., Colbeck, C., Furman, T. (2010). Increasing Diversity in the Geosciences: Recruitment Programs and Student Self-Efficacy, Journal

Ceci, S. J., Ginther, D. K., Kahn, S., \& Williams, W. M. (2014). Women in Academic Science: A Changing Landscape, Psychological Science in the Public Interest, 15(3), 75-141. https://doi.org/10.1177/1529100614541236 
425 Eaton, A. A., Saunders, J. F., Jacobson, R. K., and West, K. (2020). How gender and race stereotypes impact the advancement of scholars in STEM: Professors' biased evaluations of physics and biology post-doctoral candidates, Sex Roles,

Estrada, M., Hernandez, P.R., Schultz, P.W., Herrera J. (2018). A Longitudinal Study of 82, 127-141.

Hagni, A. M., (1984). Stress and stress management among geoscientists in the U.S. petroleum industry, Master's Thesis, Missouri Science \&Technology, $84 \mathrm{p}$.

Fouad N. A., Chang, W.H., Wan Min, S.R. (2017). Women's Reasons for Leaving the How Quality Mentorship and Research Experience Integrate Underrepresented Minorities into STEM Careers, CBE-Life Sciences Education, Vol. 17, No. 1. https://doi.org/10.1187/cbe.17-04-0066

Gonzales, L. (2019). Participation of women in the geoscience profession, Geoscience Currents Data Brief 15, American Geosciences Institute, 1-2.

Holmes, M.A., O'Connell, S., Frey, C., Ongley, L. (2008). Gender imbalance in US

452 Holmes, M. A., O'Connell, S., and Dutt, K. (2015). Women in the Geosciences: geoscience academia, Nature Geoscience, Vol 1. 
455 Huang, J., Gates, A.J., Sinatra, R., Barabási, A.L. (2020). Historical comparison of gender inequality in scientific careers across countries and disciplines, Proceedings of the National Academy of Sciences, 117 (9) 4609-4616. DOI: $10.1073 /$ pnas. 1914221117

Lincoln, A.E., Pincus, S., Koster, J.B., Leboy, P.S. (2012). The Matilda Effect in science: Awards and prizes in the US, 1990s and 2000s, Social Studies of Science, 1-14.

Newton, A. (2012). Plugging the leaks, Nature Geoscience, Vol. 5, 522. global survey on the perceptions and impacts of gender inequality in the Earth

Malcom, S.M., Hall, P. Q., Brown, J.W. (1976). The Double Bind: The Price of Being a Minority Woman in Science, American Association for the Advancement of Science, AAAS Report No. 76-R-3.

Marín-Spiotta, E., Barnes, R. T., Berhe, A. A., Hastings, M. G., Mattheis, A., Schneider, B., and Williams, B. M. (2020). Hostile climates are barriers to diversifying the geosciences, Advances in Geosciences, 53, 117-127. https://doi.org/10.5194/adgeo-53-117-2020. and space sciences, Earth and Space Science, 6, 1460-1468. https://doi.org/10.1029/2019EA000706 
486 Popp, A. L., Hall, C. A., Yılmaz, Y. A. (2020). How to combat bullying and discrimination $487 \quad$ in the geosciences, Eos, 101.

$488 \quad$ https://doi.org/10.1029/2020EO151914

490 Stokes, P.J., Levine, R., Flessa, K.W. (2015). Choosing the Geoscience Major:

491 Important Factors, Race/Ethnicity, and Gender, Journal of Geoscience

$492 \quad$ Education, 63:3, 250-263.

$493 \quad$ DOI: $10.5408 / 14-038.1$

495 Williams, C.L., Muller, C., Kilanski, K. (2012). Gendered Organizations in the New 496 Economy, Gender \& Society; 26(4):549-573.

497 DOI:10.1177/0891243212445466

499 Williams, B. M., McEntee, C., Hanson, B., and Townsend, R. (2017). The Role for a $500 \quad$ large scientific society in addressing harassment and work climate issues, Annals $501 \quad$ of Geophysics, 60, 7.

$502 \quad$ https://doi.org/10.4401/ag-7441

503

504 Witze, A. (2016). Gender bias found in Earth-science society journals, Nature. DOI:10.1038/nature.2016.20708 